\title{
Film Strength and Load Carrying Capacity of Lubricating Oils
}

\author{
Toshio Sakurai*, Tetsuro Baba* and Shoji Ohara**
}

(Received December 23, 1958)

\section{Summary}

(1) As for the relation between concentration and film strength for palmitic acid, the formation of iron soap in the solution and its concentration remarkably affected the film strength. The iron soap formed in sufficient quantities in the steel/steel indicated the maximum film strength at low concentration. Meanwhile, in case of the platinum/platinum, a higher concentration was required until the film strength indicated a definite value. The film strength was then also lower.

(2) As for the relation between film strength and temperature for palmitic acid solution, if the iron soap should be formed in sufficient quantities, large values of film strength were observed at $120^{\circ} \mathrm{C}$ for cetane solution, and at $130^{\circ} \mathrm{C}$ for the refined liquid paraffin. Meanwhile, even in the platinum/platinum, large oil film strength is observed at higher temperature. The film strength of the solution, in which the soap was not formed, greatly decreased at $60^{\circ} \mathrm{C}$ in the platinum/platinum.

(3) The adsorption energy from the cetane and decalin solution of the saturated fatty acid on the steel and platinum surface was in a range of 6.72-11.7 Kcal/mole. In case of steel/steel difference was found in the thermal critical concentration for adsorption. Especially, if the steel pieces were dipped in the solution at $100^{\circ} \mathrm{C}$ for 2 hrs., a remarkable difference was observed. This is due to the formation of iron soap, since this thermal critical concentration is associated with the oil film strength.

(4) When the film strength was calculated from the adsorption energy, the actually measured value almost agreed with the calculated value. Even if the real contact area was taken into consideration, no remarkable discrepancy was observed. In connection with the conventional Soda-type four-ball machine tests, it had not only theoretically but also experimentally been testified that the oil film collapsed even at the initial pressure of $0.5 \mathrm{~kg} / \mathrm{cm}^{2}$. In other words, it is not proper to call the four-ball machine test results the film strength.

(5) The four-ball machine test showed the following: Collapse and repair of film were always alternately repeated. In hydrocarbon oils the oxidized hydrocardon which had formed during lubrication played an important role as oiliness agents. Meanwhile, due to the existence of oxidation inhibitors, the load carrying capacity was inferior to to that of the hydrocarbon oil itself.

(6) When a comparison was made between the film strength obtained under static conditions by electrical methods, and the load carrying capacity measured

* Applied Chemistry Section, Tokyo Institute of Technology

* Present Adress Fuji Denki Seizo K.K. 
by the four-ball machine, it was shown that these two terms were quite different from each other in their physical and chemical meanings. Therefore, a distinction should be made between these two terms.

\section{Introduction}

The technical term "film strength of the lubricating oil" has not so far been properly understood. No distiction has been drawn between the load carrying capacity (and/or the antiseizure load) and the film strength of the lubricating oil in their meaning. They are liable to be confused with each other and used as though they had the same meaning. The measured values obtained by the friction testers such as the Timken friction machine, four-ball machine, etc. are directly expressed as a film strength or a load carrying capacity. Although this practical use of the terms is naturally not a mistake, it is very important to discriminate between these two terms for the nature of lubricating oil, not only to discuss the film of lubricating oil and observe many kinds of friction tester results, but also to develop the research in lubricating oil. Such being the case, the film strength has been evaluated from the adsorption energy of the adsorbate, or measured in a statical condition by employing an electrical method. In comparing these results with the observed values of the four-ball machine, we have defined a difference between the film strength and the load carrying capacity evaluated from the four-ball machine.

\section{Experimental}

\section{Apparatus and Measuring Procedure}

As previously disclosed by the authors, the measuring method for the film strength of pure substances is to utilize the rectifying effect shown by the thin film of the polar compound ${ }^{1,2)}$, which is placed between the steel plate and the steel balls. If a current of $60 \mathrm{~mA}, 4500 \mathrm{c} / \mathrm{s}$ flows to the metal interface where the polar molecules exist, part of the current is rectified. If the load between the steel plate and the steel balls is increased, the rectified current decreases exponentially and finally extinguishes itself at a certain load. This load has been defined as the film strength ${ }^{2}$. Immediately before the extinction, the current shows an unstable condition (for example, becomes extinct in a moment or counter-flows). Soon, however, the rectified current becomes stabilized and then extinct under a certain load.

The conventional measuring method for the film strength of pure compounds is to place the oil drops between the plate and the balls, or to deposit the compound layers by rubbing with a filter paper. Even when either of the two methods was employed, almost the same observed value for the film strength was obtained. In this experiment, the solution of saturated fatty acid such as palmitic acid is used. Therefore, the adsorption equilibrium of palmitic acid on the interface, especially the chemical reactions of fatty acids, in the case of steel is considered. Not only that, the adsorption equilibrium with the formed iron soap comes into question. It is, therefore, desirable for the experiment, to dip the test pieces in as much solution as possible. Thus the test plate and balls have been put into a glass vessel as shown in Fig. 1. The solution should be so high that the balls on the plate may be dipped by half. The tempera. ture has been measured by a thermometer. Meanwhile, the conductor has been directly welded to the plate and the ball slider. For the load use,

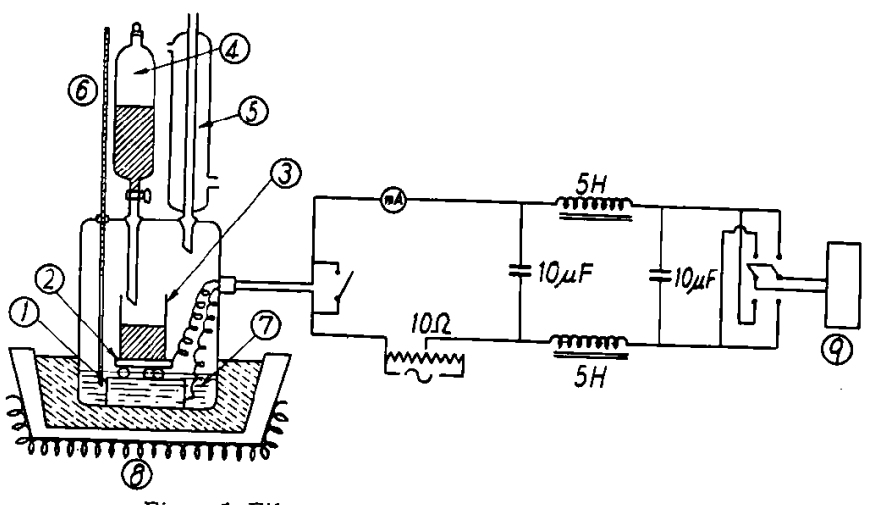

Fig. 1 Film strength measuring apparatus.

(1) Test steel plate. (2) Test ball slider. (3) Mercury vessel for the loading use. (4) Mercury dropping funnel. (5) Cooler. (6) Thermometer. (7) Oil bath. (8) Heater. (9) $\mathrm{mV}$ Meter. 
mercury has gradually been added. After the measurement, the mercury has been weighed. The weight of mercury has then been defined as the film strength.

In this experiment, solutions of palmitic acid and some polar compounds, whose solvents are cetane and refined liquid paraffin, have been prepared. The film strength has been measured between the steels, and between the platinums at the temperature range of $20-135^{\circ} \mathrm{C}$. Measurements between the platinums have been conducted after the platinum pieces have been retained for about $10 \mathrm{~min}$. at each measuring temperature. In renewing the solution for each measurement, the film strength has been evaluated from the average observed values for 3-5 times. The measurements of load carrying capacity with the Soda-type fourball machine have been in conformity with the conventional method.

\section{Lubricating oils and Specimens}

Cetane and liquid paraffin, which were used as nonpolar solvents, have been refined with fuming sulfuric acid, then ethanol-extracted and refined with active clay. They have the following properties:

Cetane; $\mathrm{d}_{4}^{20} 0.7750, \mathrm{n}_{\mathrm{D}}^{20} 1.4352$, m.p. $18.1^{\circ} \mathrm{C}$.

Decalin; $d_{4}^{20} 0.8950, n_{D}^{20} 1.4797$, b.p. $185-187^{\circ} \mathrm{C}$.

Refined liquid paraffin (which will herein after be termed "R.L.P."; $\mathrm{d}_{4}^{20} 0.8660, \mathrm{n}_{\mathrm{D}}^{20} 1.471$, molecular weight 310 , ring analysis naphthene ring $45.5 \%$, paraffin chain $54.5 \%$;

Palmitic acid, m.p. $62.4-62.6^{\circ} \mathrm{C}$, neutralization value 215.1 (calculated value 218.8 ), Stearic acid; m.p. $69.2-70.5^{\circ} \mathrm{C}$, neutralization value 197.7 (calculated value 197.3), Dodecyl Chloride; $\mathrm{n}_{\mathrm{D}}^{22} 1.4432$, $\mathrm{d}_{4}^{22} 0.8675$ (Ref. value $\mathrm{n}_{\mathrm{D}}^{22} 1.4421, \mathrm{~d}_{5}^{22} 0.8673$ ), hydrogen cetylbutlylphosphite; P 6.1\% (calculated value $5.8, \%$ ) have been used.

The steel plate used is made of block gauge materials, while the platinum plate test piece is platinum-galvanized, which did not change when it was immersed in the $6 \mathrm{~N}$ hydrochloric acid aqueous solution. The steel ball is $5 / 32$ in. 3 balls are silverbrazed to the disc (whose diameter is $20 \mathrm{~mm}$ ) in a regular triangular form. The platinum test pieces used are also platinum-galvanized.

\section{Results and Discussion}

1. Critical Temperature for the Adsorption of Palmitic Acid in Solution

Here is a problem which must be considered in measuring the film strength. When the temperature of solution is increased, a rapid change is generally found in the surface concentration of the polar compound adsorbed on the solid surface at a certain temperature. This temperature is influenced by the mutual relation between the solvent and the adsorbate as well as the concentration of adsorbate in the solution. Therefore, the critical temperature for this system must be indicated at a definite concentration of the adsorbate.

In this experimental method, the rectified current becomes extinct at each critical temperature in contrast to the case when the film is broken off by a high load. In otherwords, the extinction is caused by the disorder in the orientation of the polar molecules on the surface, or by the great reduction in the surface concentration. Such being the case, the measurements of film strength in the high temperature range cannot discriminate between the above two causes. This point has been considered adequately in our study. At any rate, it is evident that there cannot be any effective lubricating oil film when the rectified current becomes extinct.

Small quantities of palmitic acid were added to the refined solvent respectively, and 1.1 . wt.\% $\left(3.36 \times 10^{-2} \mathrm{~mole} / l\right)$ of palmitic acid-cetane solution

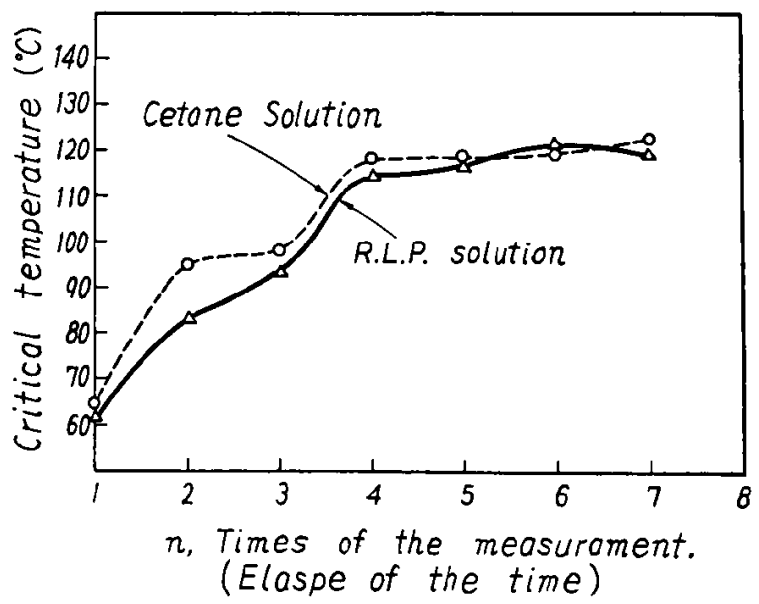

Fig. 2 Change in the critical temperature of the palmitic acid solution. 
and 1.05 wt. \% $\left(3.58 \times 10^{-2} \mathrm{~mole} / l\right)$ of R.L.P. solution had been prepared. Since these solutions were in the super saturated state at room temperature, the measurements given within a few minutes at lower temperatures. Changes in critical temperature, which were accompanied by the number of measurements (elapses of time) for the same solution between the steels, were measured for each solution of the above, and these results obtained are shown in Fig. 2.

When the temperature was gradually increased (approx. $2^{\circ} \mathrm{C} / \mathrm{min}$.) from room temperature by using the cetane solution, the 1st critical temperature appeared at $64^{\circ} \mathrm{C}$, this is close to the melting point of palmitic acid. Next, when the 1st critical temperature was dropped by about $10^{\circ} \mathrm{C}$ and again increased, the 2nd critical temperature appeared at $95^{\circ} \mathrm{C}$. When the temperature was again dropped by about $10^{\circ} \mathrm{C}$ and increased, the critical temperature became much higher. If this process was repeated, the critical temperature reached almost a definite point. This phenomenon was also found in the case with the liquid paraffin solution. If such a temperature increasing process was employed in either the cetane solution or R.L.P. solution, it took about 1.5 hours for the critical temperature to come to a definite value; if the steel pieces were dipped in the solution at $100^{\circ} \mathrm{C}$ for 1.5 hours, they could be enhanced to the definite value.

Such a phenomenon was naturally not observed between the platinums. As will be described later, therefore, the measurement of film strength in the high temperature region between the steels were made in palmitic acid solution, in which the steel plate was dipped at $100^{\circ} \mathrm{C}$ for 2 hours.

The 2nd results can be observed as follows: At first the palmitic acid adsorbed on the steel surfaces greatly decreased the surface concentration in the neighborhood of the melting point. Meanwhile, some palmitic acid molecules then possibly desorbed as palmitic acid soap. As this process is further repeated, the concentration of the palmitate increases, while the critical temperature reaches a definite value in such a sufficient concentration of the soap. If the observation is compared with the results for the platinums, the above phenomena are easily understood.

\section{Adsorption Energy}

Adsorption energy of the polar compound on the oil/solid interface can be evaluated from the adsorption isostere. Since it is difficult to accurately obtain the surface concentration of adsorbate on the oil/solid interface, indirect methods are generally used. These methods are based upon the following assumptions:

If the surface concentration reaches a certain value, the surface film established of ten shows a different nature. For instance, Frewing ") had revealed in a friction test that if the adsorbed film of an oiliness agent was heated to a certain temperature, a desorption effect caused a stick-slip from smooth sliding; Zisman and co-workers ${ }^{5)}$ found that no oleophobic monolayer was formed at the critical temperature. In our experiments, the surface concentration of the adsorbate has been greatly decreased at the critical temperature, at which no rectifying effect is observed when the temperature is increased. Thus a rapid change has been given to the nature of the adsorbed film.

Derivation of the adsorption isostere has so far been attempted by many researchers ${ }^{4,6,7,8)}$. When the authors used the Langmuir adsorption isotherm and Gibbs-Helmholz formulas, the following equation has been obtained :

$$
2.3 \log C=-\frac{U}{R T}+\text { Const. }
$$

where, $C$ is the solute concentration in the solution, $U$ the adsorption energy, $R$ the gas constant, $T$ the critical temperature $\left({ }^{\circ} \mathrm{K}\right)$.

In connection with the cetane solution of saturated fatty acid, the test results for platinum /platinum and steel/steel (measured within $10 \mathrm{~min}$. at a definite temperature) is shown in Fig. 3 and Fig. 4. Meanwhile, the adsorption energy obtained and the thermal critical concentration for adsorption (a point, in which two straight lines were discontinuous in the relation, $\log C-1 / T$, was defined) are shown in Table 1 and Table 2.

The adsorption energy in the platinum of saturated fatty acid increased with the increase in the number of carbons. In case of steel, however, little change was observed. In this connection, attention should be paid to the fact that the adsorption 


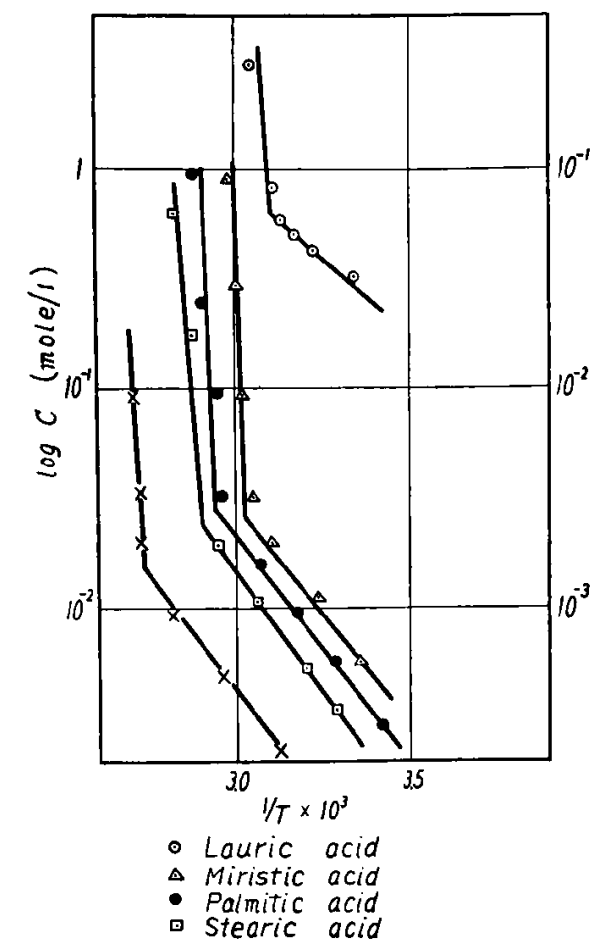

Fig. 3 Cetane solution of the saturated fatty acid (platinum/platinum).

Table 1 Adsorption energy and the critical concentration of fatty acid in fatty acid-cetane solution (Platinum/Platinum).

\begin{tabular}{c|c|c}
\hline Acid & $\begin{array}{c}\text { Adsorption } \\
\text { energy } \\
\text { Kcal/mole }\end{array}$ & $\begin{array}{c}\text { Thermal critical } \\
\text { concentration } \\
\text { mole } / l\end{array}$ \\
\hline Lauric Acid & 6.72 & $6.0 \times 10^{-1}$ \\
Miristic Acid & 9.32 & $2.4 \times 10^{-2}$ \\
Palmitic Acid & 10.4 & $2.4 \times 10^{-2}$ \\
Stearic Acid & 10.6 & $1.8 \because 10^{-2}$ \\
\hline
\end{tabular}

energy for steel is measured in co-existence with the iron soap, which is formed by the reaction between steel and fatty acid. Though there is no remarkable difference among the various fatty acids in their reactivity with steel, the adsorption energy values obtained in steel indicate almost the same value, differing from the results obtained in platinium.

Table 3 shows the test results when the steel pieces were dipped at $100^{\circ} \mathrm{C}$ for 2 hours in decalin and cetane solutions of palmitic acid. Although such a solution naturally contained some iron soap ${ }^{6}$, the adsorption energy had almost the same value. However, it was revealed that the thermal critical concentration for adsorption had noticeably shifted to the low concentration side in Fig. 3.

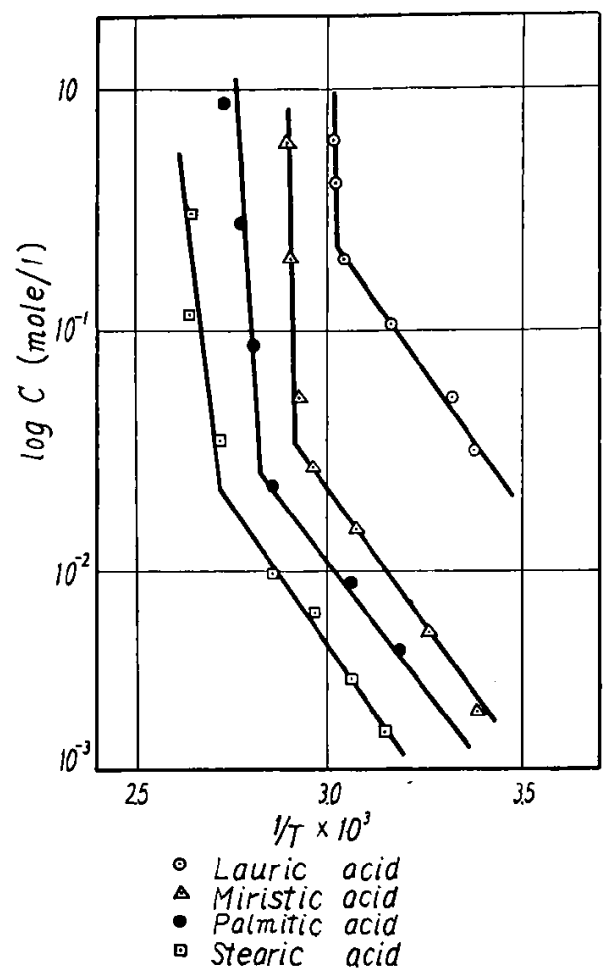

Fig. 4 Cetane solution of the fatty acid (steel/steel)

Table 2 Adsorption energy and the critical concentration of fatty acid in fatty acid-cetane solution (Steel/Steel).

\begin{tabular}{l|c|c}
\hline \multicolumn{1}{c|}{ Acid } & $\begin{array}{c}\text { Adsorption } \\
\text { energy } \\
\text { Kcal/mole }\end{array}$ & $\begin{array}{c}\text { Thermal critical } \\
\text { concentration } \\
\text { mole } / l\end{array}$ \\
\hline Lauric Acid & 11.7 & $2.8<10^{-1}$ \\
Miristic Acid & 10.4 & $3.2 \times 10^{-2}$ \\
Palmitic Acid & 10.6 & $2.4 \times 10^{-2}$ \\
Stearic Acid & 11.4 & $2.0 \div 10^{-2}$ \\
\hline
\end{tabular}

Table 3 Adsorption energy and the critical concentration of palmitic acid in decalin and cetane solutions.

\begin{tabular}{l|l|c|c}
\hline Solvent & Metals & $\begin{array}{c}\text { Adsorption } \\
\text { energy } \\
\text { Kcal/mole }\end{array}$ & $\begin{array}{c}\text { Thermal critical } \\
\text { concentration } \\
\text { mole/l }\end{array}$ \\
\hline Decalin & Platinum & 10.2 & $6.8 \times 10^{-2}$ \\
& Steel & 10.6 & $1.6 \times 10^{-2}$ \\
& Platinum* & 10.7 & $1.8 \times 10^{-3}$ \\
Cetañe & Platinum & 10.4 & $2.4 \times 10^{-2}$ \\
& Steel & 10.6 & $2.2 \times 10^{-2}$ \\
& Platinum* & 10.7 & $1.3 \times 10^{-3}$ \\
\hline
\end{tabular}

* The solution after the steel pieces being dipped at $100^{\circ} \mathrm{C}$ for $2 \mathrm{hrs}$. (6).

\section{Film Strength of Palmitic Acid Solution}

The relation between the concentration and the film strength of palmitic acid was measured at room temperature $\left(20-25^{\circ} \mathrm{C}\right)$. Meanwhile, the re- 
lation between the temperature and the film strength was evaluated at varied temperatures in the steel/steel and the platinum/platinum systems.

\subsection{Concentration and the Film Strength}

The relation between the concentration and the film strength of palmitic acid at a room temperature is shown in Fig. 5.

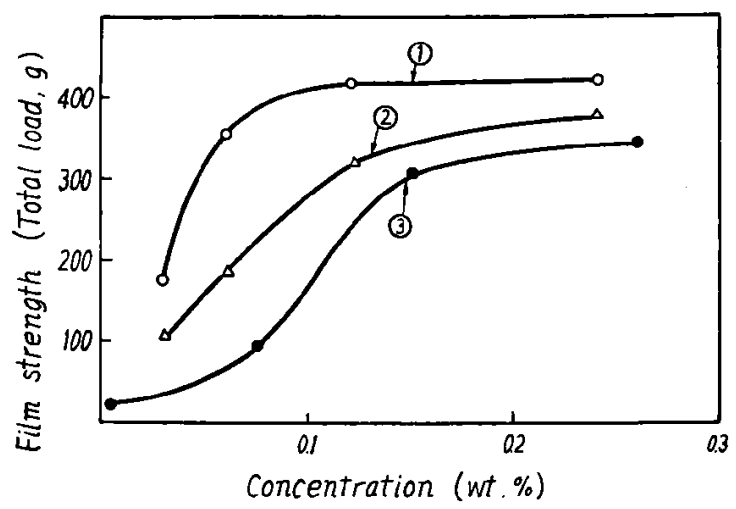

Fig. 5 Film strength-Concentration of palmitic acid solution at room temperature.

(1) : $0.24 \mathrm{wt} .96$ cetane solution which was heated with steel to $100^{\circ} \mathrm{C}$ for $2 \mathrm{hrs}$. and its diluted solution. (steel/steel).

(2): Cetane solution (steel/steel).

(3) : R.L.P. solution.

Curve 1 has been obtained when the measurements were made with the steel/steel in the dilute reacted solution in which steel pieces were dipped in the cetane solution of $2.4 \mathrm{wt} . \%$ palmitic acid at $100^{\circ} \mathrm{C}$ for $2 \mathrm{hrs}$. Curve 2 has been obtained, when the film strength was measured in the steel/steel in the solution of palmitic acid and cetane at room temperature. Curve 3 has been obtained, when the solution of palmitic acid and R.L.P. was measured in the platinum platinum at room temperature.

A comparison among the above three curves suggests to us the following: The palmitic acid seems to have formed an iron soap of relatively high concentration reacting with steel. As for the diluted solution which contains iron soap, the film strength has reached almost the upper limit value at low concentration. As shown by curve 2 , when the steel pieces were dipped at room temperature, the film strength had not reached the highest value until $0.24 \%$. If the same experiment is conducted in the platinum /platinum, a higher concentration is required for the more powerful film strength, since there is a difference in the thermal critical concentration.

It is conceivable from the above observation that the material formed in reaction plays an important role, as the solution in reaction with steel shows the highest film strength at the lowest concentration. In other words, it is probable that the formation of iron soap has an important effect upon the thermal critical concentration and consequently the film strength. If the experiment is conducted at room temperature, and not a high temperature, some palmitic acid can, however, react with a lower rate. In this case, the major part of the adsorbed film seems to be formed by palmitic acid itself, and then a higher concentration is required for higher film strength. In the platinum/platinum, the adsorbed surface films are formed by only palmitic acid; therefore, the highest concentration seems to be necessary.

\subsection{Temperature and the Film Strength}

It is natural that the strength shown by the adsorbed film changes with the increase in temperature. In order to evaluate the film strength by means of this experiment, the reaction between the solution and the steel surface is unavoidable even at low temperature in the steel/steel as previously mentioned. Experiments have, therefore, been made with cetane and R.L.P. solutions of palmatic acid, in which steel test pieces were previously dipped at $100^{\circ} \mathrm{C}$ for $2 \mathrm{hrs}$. The results are shown in Table 4 and Fig. 6. The cetane solution in reaction with the steel pieces had been measured in the platinum /platinum, and compared with the results of the platinum/platinum in palmitic acid solution it. self

As shown in Fig. 6, the solution in reaction with steel pieces-in case of either cetane or R.L.P. solution-had shown a high film strength at higher temperature in the steel/steel. At a certain temperature, however, the film strength greatly decreased. R.L.P. solution showed a higher temperature than cetane solution. The film strength of these two solutions, however, greatly decreased with the increase in tempera- 
Table 4 Film strength of Palmitic acid solution.

\begin{tabular}{|c|c|c|c|c|c|c|c|c|c|}
\hline \multirow{3}{*}{ Temp. ${ }^{\circ} \mathrm{C}$} & \multicolumn{3}{|c|}{$\begin{array}{c}1.10 \mathrm{wt} / \% \text { cetane-solution } \\
(\text { steel } / \text { steel) }\end{array}$} & \multicolumn{3}{|c|}{$\begin{array}{c}1.05 \text { wt } 96 \text { R.L.P. solution } \\
\text { (steel/steel) }\end{array}$} & \multicolumn{3}{|c|}{$\begin{array}{c}1.10 \mathrm{wt} \% \text { cetane-solution } \\
(\mathrm{Pt} / \mathrm{Pt})\end{array}$} \\
\hline & \multirow[b]{2}{*}{$\begin{array}{c}\text { Total Load } \\
\qquad \mathrm{g}\end{array}$} & \multicolumn{2}{|c|}{ Hertz Load } & \multirow{2}{*}{$\begin{array}{c}\text { Total Load } \\
\mathrm{g}\end{array}$} & \multicolumn{2}{|c|}{ Hertz Load } & \multirow[b]{2}{*}{$\begin{array}{c}\text { Total Load } \\
\mathrm{g}\end{array}$} & \multicolumn{2}{|c|}{ Hertz Load } \\
\hline & & $\begin{array}{c}\text { Pav } \\
\mathrm{kg} / \mathrm{mm}^{2}\end{array}$ & $\begin{array}{c}\text { Pmax } \\
\mathrm{kg} / \mathrm{mm}^{2}\end{array}$ & & $\begin{array}{c}\operatorname{Pav} \\
\mathrm{kg} / \mathrm{mm}^{2}\end{array}$ & $\begin{array}{c}\text { Pmax } \\
\mathrm{kg} / \mathrm{mm}^{2}\end{array}$ & & $\begin{array}{c}\text { Pav } \\
\mathrm{kg} / \mathrm{mm}^{2}\end{array}$ & $\begin{array}{c}P \max \\
\mathrm{kg} / \mathrm{mm}^{2}\end{array}$ \\
\hline $\begin{array}{l}20 \\
25 \\
40 \\
50\end{array}$ & $\frac{\overline{425}}{4 \overrightarrow{45}}$ & $\begin{array}{r}66.3 \\
67.4\end{array}$ & $\begin{array}{r}99 . \overline{5} \\
101 . \overline{1}\end{array}$ & $\begin{array}{l}425 \\
430 \\
-\end{array}$ & $\begin{array}{r}62.2 \\
-\overline{7} \\
66.7\end{array}$ & $\begin{array}{r}99.3 \\
100.1 \\
-\end{array}$ & $\begin{array}{c}340 \\
340 \\
200\left(42^{\circ} \mathrm{C}\right) \\
-\end{array}$ & $\begin{array}{r}61.6 \\
61.6 \\
53.5 \\
\end{array}$ & $\begin{array}{r}92.4 \\
92.4 \\
80.3 \\
-\end{array}$ \\
\hline 60 & 420 & 65.8 & 98.7 & 427 & 66.2 & 99.3 & 100 & 41.8 & 62.7 \\
\hline $\begin{array}{l}70 \\
80\end{array}$ & - & - & - & $\overline{430}$ & $66 \overline{7}$ & $100 \overline{.1}$ & 50 & $\begin{array}{r}34.0 \\
-\end{array}$ & $\begin{array}{r}51.0 \\
-\end{array}$ \\
\hline 85 & 430 & 66.7 & 100.1 & $-\ldots$ & - & & $\ldots$ & - & - \\
\hline $\begin{array}{l}100 \\
110\end{array}$ & $\begin{array}{l}380 \\
350\end{array}$ & $\begin{array}{l}62.6 \\
62.1\end{array}$ & $\begin{array}{l}95.6 \\
93.2\end{array}$ & $\begin{array}{r}390 \\
-\end{array}$ & $\begin{array}{r}64.1 \\
-\end{array}$ & $\begin{array}{r}94.2 \\
-\end{array}$ & E & - & - \\
\hline 120 & $\overline{75}$ & $\overline{38}$ & $57 ?$ & 380 & 63.7 & 95.6 & - & - & - \\
\hline 125 & 75 & 38.1 & 57.2 & & & & - & - & - \\
\hline 130 & - & - & - & 380 & 63.7 & 95.6 & - & - & - \\
\hline 135 & - & - & - & 110 & 43.1 & 64.7 & - & - & - \\
\hline
\end{tabular}

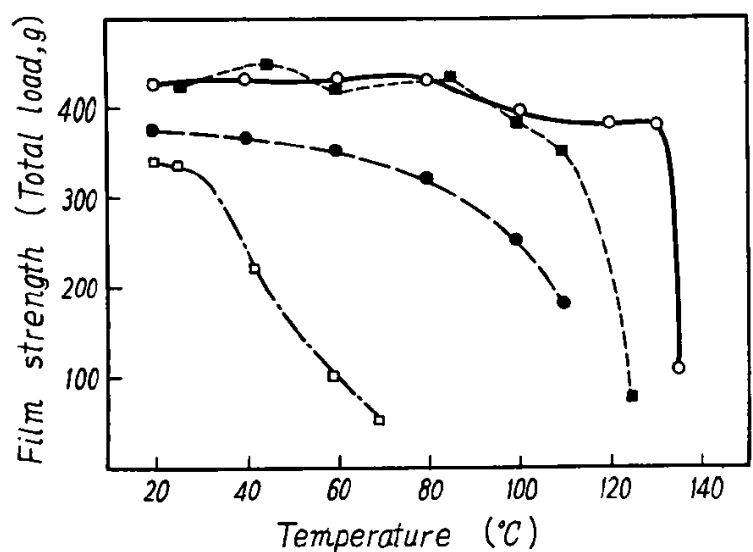

-O- $1.0 \mathrm{wt} . \%$ R.L.P. solution (steel/steel).

$-\square-1.10 \mathrm{wt} . ;$ Cetane solution

(platinum/platinum)

- $1.10 \mathrm{wt} . \%$ cetane solution which was heated with steel to $100^{\circ} \mathrm{C}$ for $2 \mathrm{hrs}$.

1.10 wt. $\%$ cetane solution.

Fig. 6 Temperature-Film strength of the palmitic acid solution.

ture. Even when the solution reacted with steel was used in the platinum/platinum, the result was close to that in the steel/steel, differing very much from that in the platinum/platinum for palmitic acid solution itself. The same trend observed in the steel/steel and the platinum /platinum for the reacted solution indicated that the soap formed in reaction with steel in the solution played an important role. It is then considered that these behaviors are connection with the micelle formation of iron soap, a main body of the reactants ${ }^{6}$. The reason why the same solution shows somewhat different per- formance between the steel/steel and the platinum/platinum seems to come from the fact that the reaction of the still unreacted palmitic acid molecules takes place on the steel surfaces during the adsorption process. It is interesting that there is found a remarkable difference between the palmitic acid solution and its reacted solution for the platinum/platinum. It is evident that this difference is attributed to the formation of iron soap, an reaction resultant.

\section{Observation on the Film Strength}

\subsection{Calculation of the Film Strength from the Adsorption Energy}

If it is assumed that the film strength of lubricating oils is the oil resistance leading to the contact between solids when the primary oil film between solid surfaces is collapsed, such large strength cannot be expected. Under a dynamic condition, the hot spot would be immediately covered with the oil film, even if the films is collapsed.

In a broad sence, an oil film is formed by the flow of a lubricating liquid. As a process, however, the film is formed by the oil spread over the solid surface. What is important here is whether the hot spots are wetted with this fluid or not. As for the "film strength" called in the dynamic condition, such a film is hardly formed by mechanical effects and the temperature increase of the friction parts, while the repaircapability of the oil film greatly decreases and 
finally leads to seizure. The load under these conditions is often called the "film strength".

The above "film strength" is quite different in meaning from the film strength measured by the authors. We have tried to calculate from the adsorption energy of the molecules forming the oil film, the load caused when the oil film formed by some kind of surface active agents is dynamically broken.

As the desorption energy of the oil film at the interface can be evaluated from adsorption isostere, the load for breaking of the film of a certain thickness can be calculated from this energy.

Now we assume that the stearic acid is oriented on the geometric plane surface of the solids. The adsorption energy of stearic acid molecules per unit area $\left(\mathrm{mm}^{2}\right)$ is then $U n / N . U$ is the adsorption energy (Kcal/mole), $N$ the Avogadro's number and $n$ the number of molecules per unit area. If it is assumed that the rupture is caused in a state of monolayer or double layers when the film is broken, and that the thickness of film is $d$, the film strength of stearic acid can be obtained by the following expression.

Film Strength $=(U n / N d) f$,

where, $f$ is a conversion factor. In obtaining the number of molecules per unit area, the following

Table 5 Adsorption energy and the film strength.

\begin{tabular}{l|cc|c|c}
\hline \multirow{2}{*}{ Metals } & $\begin{array}{c}\text { Adsorption } \\
\text { energy } \\
\end{array}$ & $\begin{array}{c}\text { Film Strength } \\
\left(\mathrm{kg} / \mathrm{mm}^{2}\right)\end{array}$ \\
\cline { 3 - 5 } & 13.0 & Ref. (4) & 18.0 & 90.0 \\
\hline Steel/Steel & 11.4 & Ref. (6) & 15.7 & 78.7 \\
Steel/Steel & 10.0 & Ref. (7) & 13.8 & 69.0 \\
Platinum/Platinum & $10.25 \AA$ & $\mathrm{d}=5 \mathrm{~A}$ \\
\hline
\end{tabular}

values have been employed : $20.5 \AA$ sq for the occupied area of a stearic acid molecule on the solid surface by using the one for the water surface, $11.4 \mathrm{Kcal} / \mathrm{mole}$ (cetane) previously obtained for the adsorption energy in the steel $/ \mathrm{steel}, 13.0 \mathrm{Kcal} / \mathrm{mole}$ (white oil), and $10.0 \mathrm{Kcal}$ /mole (dicyclohexyl) in the platinum/platinum. The results calculated are shown in Table 5 . When the film collapses in the state such that the molecules are vertically oriented on the interface, the thickness $d$ is maximum, and when the film collapses in such a manner that the molecules fall down on the local, sharp and convex section, the thickness $d$ is minimum. On the other hand, there are generally the intermediate cases when the molecules have some inclination between the two extremes.

It is assumed that the extreme values of $d$ for the former two cases are $25 \AA$ and $5 \AA$ respectively in calculating the film strength.

As disclosed in the Table 5, the film strength for the steel/steel is $15.7-90.0 \mathrm{Kg} / \mathrm{mm}^{2}$, while that for the platinum/platinum is $13.8-69.0 \mathrm{Kg}$ $/ \mathrm{mm}^{2}$. These values are compared with the observed values for the film strength of stearic acid and R.L.P. solution (1.59 wt.\%) in the Table 6.

As revealed in Table 6 , the actually measured values of the film strength of the rubbed stearic acid film and the R.L.P.-stearic acid (1.59\%) agree with the calculated values in their order. The same results are obtained, even if there are double molecular layers between the solid/solid interface.

\section{2 Load Carrying Capacity Measured by the Four-Ball Machine}

Table 6 Friction coefficient and the film strength (steel/steel)

\begin{tabular}{l|c|c|c|c|c}
\hline \multicolumn{1}{c|}{ Lubricating Oils } & Additives & Friction Coeffi- & \multicolumn{3}{|c}{ Film Strength } \\
\cline { 3 - 6 } & Total Load & \multicolumn{2}{|c}{ Hertz Load } \\
\hline $\begin{array}{l}\text { (wient } \\
\text { Pav }\end{array}$ & - & 0.10 & 510 & 69.6 & 104 \\
Stearic acid (rubbed film) & - & 0.45 & - & - & - \\
Refined Liquid Paraffin & 1.59 & 0.12 & 382 & 63.1 & 94.7 \\
R.L.P. + Stearic acid & 1.32 & 0.19 & 441 & 66.5 & 99.8 \\
R.L.P. + Dodecyl chloride & 1.63 & 0.16 & 335 & 60.8 & 91.2 \\
R.L.P. + Cetylbutyl phosphite & & &
\end{tabular}

* Film strength of pure hydrocarbon can not be measured. 
Table 7 Four-ball machine test results obtained when the additives are added to liquid paraffin. (total load $0.5,2.0 \mathrm{~kg} / \mathrm{cm}^{2}, 20 \mathrm{rpm}, 20 \mathrm{~min}$.)

\begin{tabular}{|c|c|c|c|c|c|c|c|c|}
\hline \multirow{3}{*}{ Lubricating Oils } & \multicolumn{2}{|c|}{ Additives } & \multicolumn{4}{|c|}{$\begin{array}{l}\text { Average Scar dia. (lower balls) and } \\
\text { Average Scar band (upper ball) (mm) }\end{array}$} & \multicolumn{2}{|c|}{ Seizure Load } \\
\hline & \multirow{2}{*}{ Wt 8} & \multirow{2}{*}{ Mole } & \multicolumn{2}{|c|}{$\begin{array}{l}\text { Total Load } \\
\left(0.5 \mathrm{~kg} / \mathrm{cm}^{2}\right)\end{array}$} & \multicolumn{2}{|c|}{$\begin{array}{l}\text { Total Load } \\
\left(2.0 \mathrm{~kg} / \mathrm{cm}^{2}\right)\end{array}$} & \multirow{2}{*}{$\mathrm{Kg} / \mathrm{cm}^{2}$} & \multirow{2}{*}{$\begin{array}{l}\mathrm{P}_{\max } \\
\mathrm{Kg} / \mathrm{mm}\end{array}$} \\
\hline & & & Scar band & Scar dia. & Scar band & Scar dia. & & \\
\hline Refined Liquid Paraffin & - & - & $0.21 \sim 0.46$ & 0.44 & $0.49 \sim 0.60$ & 0.64 & 5.0 & 486 \\
\hline R.L.P. + Calco MB & 0.60 & - & - & - & $0.56 \sim 0.72$ & 0.64 & 4.0 & 449 \\
\hline R.L.P. + Stearic acid & 1.59 & 0.48 & $0.19 \sim 0.43$ & 0.42 & $0.46 \sim 0.61$ & 0.60 & 5.5 & 501 \\
\hline R.L.P. + Cetyl butyl phosphite & 1.63 & 0.43 & $0.19 \sim 0.37$ & 0.36 & $0.42 \sim 0.49$ & 0.50 & 12.5 & 614 \\
\hline R.L.P. + Dodecyl chloride & 1.32 & 0.49 & $0.31 \sim 0.41$ & 0.38 & $0.32 \sim 0.50$ & 0.55 & 9.0 & 592 \\
\hline
\end{tabular}

Table 7 , shows the results of the test given by the conventional four-ball machine when various kinds of additive were added almost in the same moles to R.L.P. The additives used were stearic acid, dodecyl chloride, hydrogen cetylbutylphosphite and the Calco MB.

In Table 7, a comparison should be made between R.L.P. and Calco MB (oxidation inhibitor) added to R.L.P. Almost the same results are observed as those obtained by Takahashi ${ }^{(9)}$, and Toyoguchi's ${ }^{(10)}$ recent results. If other additives are added, however, the load carrying capacity is generally more than that for R.L.P. This means that these surface active agents are effective as oiliness agents or extreme-pressure additives.

\subsection{Film Strength and the Load Carrying Capacity}

The "Film strength" so far obtained in a dynamic status has an extremely large value (Pmax) of $486-619 \mathrm{~kg} / \mathrm{mm}^{2}$ as shown in the Table 7. The value obtained from the adsorption energy is less than the above value. It is naturally considered that a large film strength cannot actually be expected from organic surface films.

If so, why is such a large load carrying capacity obtained? Aside from the extreme-pressure type, the extremely high value (Pmax $486 \mathrm{~kg}$ $/ \mathrm{mm}^{2}$ ) can be obtained even for R.L.P. It is, however, evident from Table 7 that this value is not the true film strength, and that the friction wears are easily caused by the load of 0.5 $\mathrm{kg} / \mathrm{cm}^{2}$, an initial pressure of the four-ball machine. It is, therefore, understood that the true film strength is less than this load. What is interesting here is the results of the reaction in which $0.5 \%$ of the oxidation inhibitor Calco MB was added to R.L.P. The load carrying capacity for the oil in which the oxidation inhibitor is added is less than that for R.L.P. From these results, it is conceivable that the film had collapsed under the initial pressure and caused a contact between the metals, when the load carrying capacity was tested. The oil performance of repairing the hot spots caused by the contact of two solid surfaces is due to the effects, which result from oil drawn to the gap under mechanical conditions, aud the oil spread over the surfaces. The spreading of oil is influenced by the kind of surface active agents in the oil.

Under the test conditions of the four-ball machine, it is naturally possible that some kinds of oiliness agents are formed by the oxidation of hydrocarbon oils. It is, therefore, probable that the load carrying capacity of the inhibited oil would be lower than that of R.L.P., if the oxidation inhibitor is added to R.L.P., because Calco MB, which is active as an oxidation inhibitor, is not a good oiliness agent. If any good oiliness agent is added, the load carrying capacity increases as shown in Table 7 . The experiments have revealed that the phosphite ester and chloride have the nature of being extremepressure agents in their performance. It, therefore, seems to be unreasonable to call the load carrying capacity of such oils as the "film strength", since the experiments have given a higher strength than that possesed by the film itself.

Now, we will observe the difference between 
the film strength obtained under static conditions, and that calculated from the adsorption energy. This will be defined by considering the real contact area of the plate and the ball. When the oil film between the solids is torn, and the metals are in contact with each other, the actually measured values of film strength and load carrying capacity are the values for the apparent contact area obtained from the Hertz formula. It is, therefore, conceivable that the actual contact between the metals is to be made on the smaller real contact area than the apparent one.

If the real contact area causes a plastic flow in the contact region with the metals, the real contact area can be evaluated from the Bowden's formula $A=W / P m . \quad A$ is the real contact area, $P m$ the mean yield pressure, and $W$ the load.

When the stearic acid rubbed film shows a film strength Pav (total load $510 \mathrm{~g}, 170 \mathrm{~g}$ per ball) $=69.7 \mathrm{~kg} / \mathrm{mm}^{2}$, the real contact area is calculated as $P m-200 \mathrm{~kg} / \mathrm{mm}^{2}, 8.5 \times 10^{-4} \mathrm{~mm}^{2}$. And, the area of the contact circle obtainable from the Hertz formula is $24.4 \times 10^{-4} \mathrm{~mm}^{2}$. Therefore, the apparent contact area is 2.9 times as much as the real contact area. Considering the real contact area, the real values of the film strength would be larger than the actually measured values-more in proportion to the value for the real contact area.

In connection with the above difference between the actually measured value and the calculated value, the calculated value has been computed from the energy of adsorption, probably a physical adsorption. It is, however, evident that a chemical reaction can take place between the fatty acid and steel even at room temperature. Should we imagine only the physical ad. sorption phenomenon under the actual measurement conditions?

If we suppose that the chemical adsorption stage is included, we can expect greater values. Or we can suppose that when such a load is given, some film in the region of the apparent contact area is not perfectly extruded from the region under higher pressure, but remain in the concave section. It is also feasible to consider that the remarkable increase in viscosity is forced, and the oil with increased viscosity behaves as a material of plasticity and differs from the initial oil, and so the film bears a load in a status close to the apparent area.

From the above observation, it is conceivable that the reason for the little difference between the measured value and the calculated value can be explained, though it is not evident which factor is the major direct cause therefore. At any rate, it is obvious that any large strength cannot be expected from the lubricating oil film.

As disclosed in Table 7, the Soda-type fourball machine test showed that the oil film collapsed, even at the initial pressure of 0.5 $\mathrm{kg} / \mathrm{cm}^{2}$ and that the metals were in contact with each other. When various kinds of additives are added to R.L.P., the load carrying capacity of used oils indicates a range of $2.5-12.5 \mathrm{~kg} / \mathrm{cm}^{2}$, and becomes larger or smaller than that of the original oil in accordance with the kind of additives. From where does such difference come? Why does the load carrying capacity indicate such a magnitude, even if the film showed collapse?

In order to answer the above questions, we must consider the hydrodynamic problem. The important problem, however, is the surface chemical nature and the extreme-pressure performance of the oil. Further study should be given to this problem. However, as large strength of the oil film itself cannot be expected, a distinction should be made between the terms "Film strength" and "load carrying capacity". In practical lubrication, evidently the importance lies in the load carrying capacity of the oil.

\section{References}

1) V. Vieweg and J. Kluge, Arch, Eisenhittenwessen, 2, 805 (1929); V. Vieweg, Koll. Ztschr., 61, 198 (1932).

2) T. Sakurai and A. Furusawa, J. Chem. Soc. Japan, Ind. Chem. Sec., 55, 245, 247, 309, 487 (1952).

3) T. Sakurai, A. Furusawa and T. Baba, J. Chem. Soc. Japan, Ind. Chem. Sec., 66, 193 (1953).

4) J.J. Frewing, Proc. Roy. Roc., 181 A, 23 (1942)

5) W.C. Bigelow, E. Glass and W.A. Zisman, Colloid Sci., 2, 263 (1947).

6) T. Sakurai and T. Baba, J. Japan Petroleum Inst. 1, 33 (1958).

7) W.C. Bigelow, E. Glass and W.A. Zisman, Colloid Sci., 2, 563 (1947).

8) D.J. Grisp, Colloid Sci., 11, 356 (1956).

9) H. Takahashi, Hitachi Review, 36, 1171 (1954).

10) M. Toyoguchi and Y. Takai, J. Japan Petroreum Inst. 1, 28 (1958). 